Marshall, D.E. 1984a. Mechanized pepper harvesting and trash removal, p. 276-279. Proc. $1^{\text {st }}$ Int. Conf. on Fruit, Nut and Vegetable Harvesting Mechanization, Bet Dagan, Israel. Amer. Soc. Agr. Eng. Publ. 5-84

Marshall, D.E. 1984b. Horticultural requirements for mechanical pepper harvesting, p. 389-396. Proc. $1^{\text {st }}$ Intl. Conf. on Fruit, Nut and Vegetable Harvesting Mechanization, Bet Dagan, Israel. Amer. Soc. Agr. Eng. Publ. 5-84.

Marshall, D.E. 1986. Recovery and damage of mechanically harvested peppers. Trans. Amer. Soc. Agr. Eng. 29:398-401.

Marshall, D.E. 1997. Designing a pepper for mechanical harvest. Capsicum Eggplant Nwsltt. 16:15-27.

Marshall, D.E. and B.N. Boese. 1998. Breeding capsicum for mechanical harvest, Part 2-Equipment. Proc. 10th Eucarpia Meeting on Genetics and Breeding of Capsicum and Eggplant, Avignon, France. 10:61-64.

Marshall, D.E., M.G. Pickett, and T.A. Esch. 1990. Using air to convey mechanically harvested peppers. Trans. Amer. Soc. Agr. Eng. 33:47-50.

McCullough, M.D., J.E. Motes, and B.A. Kahn. 1995. Soil bedding treatments improve pepper plant anchorage. HortScience 30:1202-1204.

New Mexico Agricultural Statistics Service. 2000. New Mexico agricultural statistics. N.M. Dept. Agr., Las Cruces.

Palevitch, D.S. Harel, J. Kanner, and I. Ben-Gera. 1975. The effects of pre-harvest dehydration on the composition of onceover harvested sweet paprika. Scientia Hort. 3:143-148

Palevitch, D. and A. Levy. 1984. Horticultural aspects of mechanized sweet pepper harvesting, p. 397-403. Proc. 1st Int. Conf. on Fruit, Nut and Vegetable Harvesting Mechanization, Bet Dagan, Israel. Amer. Soc. Agr. Eng. Publ. 5-84.

Setiamihardja, R. and D.E. Knavel. 1990. Association of pedicel length and diameter with fruit length and diameter and ease of fruit detachment in pepper. J. Amer. Soc. Hort. Sci. 115:677-681.

Sims, W.L., D. Ririe, R.A. Brendler, M.J. Snyder, D.N. Wright, V.H. Schweers, and P.P. Osterli. 1974. Factors affecting ethephon as an aid in fruit ripening of peppers. Calif. Agr. 28(6):3-4.

Wolf, I. and Y. Alper. 1984. Mechanization of paprika harvest, p. 265-275. Proc. $1^{\text {st }}$ Int. Conf. on Fruit, Nut and Vegetable Harvesting Mechanization. Bet Dagan, Israel. Amer. Soc. Agr. Eng. Publ. 5-84.

\section{Resistance of Hosta Cultivars to Petiole Rot Caused by Sclerotium rolfsii var. delphinii}

\author{
Brooke A. Edmunds, \\ Mark L. Gleason, and \\ Stephen N. Wegulo
}

AdDitional INDEX WORDs. soilborne diseases, herbaceous perennials

Summary. Eighteen cultivars of hosta (Hosta spp.), selected to represent a wide range of size, leaf shape and color, and genetics, were evaluated for reaction to Sclevotium rolfsii var. delphinii in a greenhouse in Ames, Iowa in 2000 and 2001. Bare-root, single-eye plants were planted in 15.2 $\mathrm{cm}$ (6-inch) pots in a soil-containing (2000) and soilless (2001) mix and grown in a greenhouse for 3 months. Plants were then inoculated by placing a carrot disk infested with mycelium of $S$. rolfsii at the base of the plant. Disease severity was assessed weekly for 6 weeks as percent symptomatic petioles. Disease development varied significantly $(P<0.05)$ among cultivars. Overall, 'Lemon Lime', 'Munchkin', 'Nakaiana', 'Platinum Tiara', and 'Tardiflora' had the most severe symptoms and 'Halcyon' showed the least disease.

$\mathrm{P}$ etiole rot of hosta was once thought to be confined to the southern U.S. Increasing reports of petiole rot in the midwest U.S. during the past decade, however, have caused concern among wholesale producers and homeowners.

Petiole rot, which has many other common names including southern blight, white mold, stalk rot, and crown rot, is caused by one of two fungi depending on location. Sclerotium rolfsii is widespread in areas with warm temperate winters such as the southern U.S (Aycock, 1966). A closely related fungus, Sclerotium rolfsii var. delphinii, is tolerant of cooler temperatures and is found in the northern and midwestern U.S (Harlton et al.,

Department of Plant Pathology, Iowa State University, 351 Bessey Hall, Ames IA 50010.
1995). This geographic distribution pattern has been noted through an informal survey of plant pathologists, but a comprehensive assessment of disease distribution has not been done.

The taxonomic status of Sclerotium rolfsii var. delphinii is not fully resolved. Although it was initially considered to be a separate species, Sclerotium delphinii, recent genetic studies suggest that the fungus should be considered a subspecies, Sclerotium rolfsii var. delphinii (Harlton et al., 1995; Okabe et al., 1998). In another study, Sclerotium rolfsii differed from Sclerotium rolfsii var. delphinii in optimal growth temperature, host range, colony morphology, and size of sclerotia (Punja and Damiani, 1996). Further studies are needed to conclusively determine the taxonomic designation of this fungus (Harlton et al., 1995; Okabe et al., 1998; Punja and Damiani, 1996). In any case, both fungi produce similar symptoms on hosta and are managed similarly.

Sclerotium rolfsii var. delphinii attacks the base of petioles and crown tissue, causing yellowed, wilted, easily detached petioles and, in severe cases, death of entire crowns (Edmunds et al., 2000). Bases of diseased petioles become brown and softened. White mycelium may occur on either the plant tissue or the surface of the surrounding soil. Sclerotia, the overwintering bodies of the fungus, will be present as numerous, $1.1-$ to $2-\mathrm{mm}$ diameter $(0.04$ - to 0.08 -inch), reddish-brown spheres on the soil or infected tissues. Sclerotia are the most important diagnostic indicator of petiole rot, and enable the fungus to survive in the soil for two or more years (Javed and Coley-Smith, 1973). Sclerotia attached to the crowns are also probably the primary means of longdistance dissemination.

Management of petiole rot is usually directed at preventing dissemination and germination of the sclerotia. Fungicides such as flutolanil and pentachloronitrobenzene (PCNB) can be used, but large volumes are typically necessary (Edmunds et al., 2000; Punja, 1985). Cultural strategies, such as deep burial of the sclerotia and infected plant material and rotation to nonhost species, are only partially effective in managing hosta petiole rot (Punja, 1985). Information on levels of genetic resistance among hosta cultivars is almost nonexistent. Anecdotal 
reports suggested that certain cultivars with large leaves, and those whose leaves are blue in color, are more tolerant of S. rolfsii var. delphinii-induced petiole rot (Draheim, 1997), but no controlled studies have been done.

The objectives of this study were to 1) develop a convenient and effective inoculation method for $S$. rolfsii var. delphinii on hosta and 2) screen a group of commonly planted hosta cultivars to determine the range of resistance within these cultivars.

\section{Materials and methods}

Pathogen isolation. The isolate used in this study was recovered from soil surrounding symptomatic hosta plants on the Iowa State University campus in Ames in 2000. The isolate was identified as $S$. rolfsii var. delphinii on the basis of sclerotia size and color (Z. Punja, personal communication). The fungus was stored as dry sclerotia in glass vials at room temperature.

DEVElopment of INOCUlation METHOD. The first inoculum source tested was sclerotia (Trial l). Sclerotia were produced on autoclaved kraft paper from mycelium growing on inoculated oats (Canaday, 1999). Three sclerotia were placed on the growing medium surface at the base of each of 12 hostas. Three-month-old singleeye crowns of 'Royal Standard' in 15.2$\mathrm{cm}$ pots with a greenhouse mix $(50 \%$ peat : $30 \%$ perlite : $20 \%$ steamed soil) were used for all preliminary trials. The inoculated plants were placed in a growth chamber with $12 \mathrm{~h}$ light at $23.9^{\circ} \mathrm{C}\left(75^{\circ} \mathrm{F}\right)$ and rated for disease severity after 2 weeks.

The sclerotia showed high levels of contamination by Penicillium after growth chamber inoculation. In subsequent preliminary trials, therefore, we attempted to surface sterilize sclerotia by soaking them for three $\mathrm{min}$ in a $1: 9$ dilution of $5.25 \%$ sodium hypochlorite (bleach), rinsing in distilled water, and drying between paper towels. Three surface-sterilized sclerotia were placed at the base of each of 12 hostas in a growth chamber with a 12 h light-dark regime at $23^{\circ} \mathrm{C}\left(73.4^{\circ} \mathrm{F}\right)$. Disease severity was assessed after 2 weeks.

In Trial 2, the inoculum tested was mycelium plugs $[0.9-\mathrm{cm}(0.35-$ inch) diameter] of S. rolfsiivar. delphinii that were taken from the edge of an active 1 -week-old culture growing on potato dextrose agar. A single plug was placed on the growing medium surface in contact with the base of each of 12 hostas. The plants were grown in a growth chamber with a 12 -h lightdark regime at $23^{\circ} \mathrm{C}$ and disease severity was assessed after 2 weeks.

In the third trial, we used a method adapted from a study of soybean (Glycine $\max$ ) resistance to Sclerotinia sclerotiorum, the fungus that causes white mold on many crops (Cline and Jacobsen, 1983). Inoculum was produced by transferring a $0.9-\mathrm{cm}$-diameter plug from the edge of an actively growing, 1-week-old culture of $S$. rolfsii var. delphinii grown on potato dextrose agar onto a 0.5 -cm-thick $(0.20$ inch), 0.9-cm-diameter, autoclaved carrot disk. The inoculated carrot disks were incubated for $2 \mathrm{~d}$ at $27^{\circ} \mathrm{C}(80.6$ ${ }^{\circ} \mathrm{F}$ ) in unsealed plastic petri dishes placed in plastic crispers, then were placed at the base of each of 12 hostas. The soil surface of six pots was covered with plastic to maintain high humidity at the inoculation site. No plastic was applied to the other six pots. The plants were placed in a growth chamber with a 12-h light-dark regime at $23^{\circ} \mathrm{C}$ and observed for disease severity after 2 weeks.

SCREENING OF CULTIVARS FOR DISEASE RESISTANCE. Eighteen hosta cultivars, selected to represent a wide range of plant size, leaf shape and color, and genetics (P. Henley, personal communication), were evaluated for resistance to $S$. rolfsii var. delphinii in a greenhouse at Iowa State University during the summers of 2000 and 2001.

Bare-root 3-year-old plants were obtained from Wade and Gatton Nursery (Beltsville, Ohio) and Mid-American Gardens (Salem, Ore.). Crowns were divided into single-eye plants using a sterile knife or razor blade, then planted into $15.2-\mathrm{cm}$ plastic pots in a greenhouse potting mix ( $50 \%$ peat : $30 \%$ perlite : $20 \%$ steamed soil) in 2000, and Universal Mix (Sun Gro Horticulture, Pine Bluff, Ark.) in 2001. Plants were grown in the greenhouse at more than $60 \%$ relative humidity, maintained with an Aquafog Humidifan Turbo XE 500 fogger (Jaybird Manufacturing Inc., State College, Pa.) under a $50 \%$ shade cloth for 3 to 5 months before inoculation. Plants were watered weekly and fertilized biweekly with Excel 17-5-16 (17N-2.2P-13.3K; Miracle-Gro,
Marysville, Ohio). Flower stalks were removed as they appeared.

Plant height was measured from the soil line to the tip of the topmost leaf and maximum spread of foliage was measured from leaf tip to leaf tip. Data from all plants of each cultivar were averaged to determine mean height and width.

Plants were inoculated on 13 July 2000 and 10 July 2001. The infested carrot disks were prepared as described above. After the disks were incubated for $2 \mathrm{~d}$, plants were inoculated by placing a disk on the soil surface in contact with the crown of each plant. Humidity was maintained at the inoculation site by covering the surface of the growing media with clear plastic.

Plants were rated for disease severity weekly for 6 weeks from midJuly through late August. Disease severity was assessed as percent symptomatic petioles, which was determined by counting the number of symptomatic petioles per plant and dividing by the total number of petioles per plant. Symptomatic petioles were defined as petioles with yellowing leaf blades that were easily detachable from the crown and/or showed a brown discoloration and softening of the tissue at the base.

The 18 hosta cultivars were arranged in a randomized complete block with six single-plant replications. The experiment was repeated once. Noninoculated plants of each cultivar in each replication served as controls for visual comparison to inoculated plants.

Area under the disease progress curve (AUDPC) was calculated from these assessments (Gomez and Gomez, 1984). AUDPC data were analyzed using the GLM procedure of SAS (SAS Institute, Cary, N.C.). The least significant difference test (Steel et al., 1997) was used to compare AUDPC means among cultivars.

\section{Results}

Development of inoculation METHOD. Surface sterilization of sclerotia with $10 \%$ bleach initially reduced contamination of sclerotia, but Penicillium growth resumed within one week after growth chamber incubation began. Mycelium plugs used as inoculum sometimes desiccated before infections were initiated. Disease severity was sporadic among the plants in these initial trials. Inoculating plants 
Table 1. Area under the disease progress curve (AUDPC) $)^{\mathrm{z}}$ values of hosta cultivars inoculated with the crown rot fungus, Sclerotium rolfsii var. delphinii during 2000 and 2001.

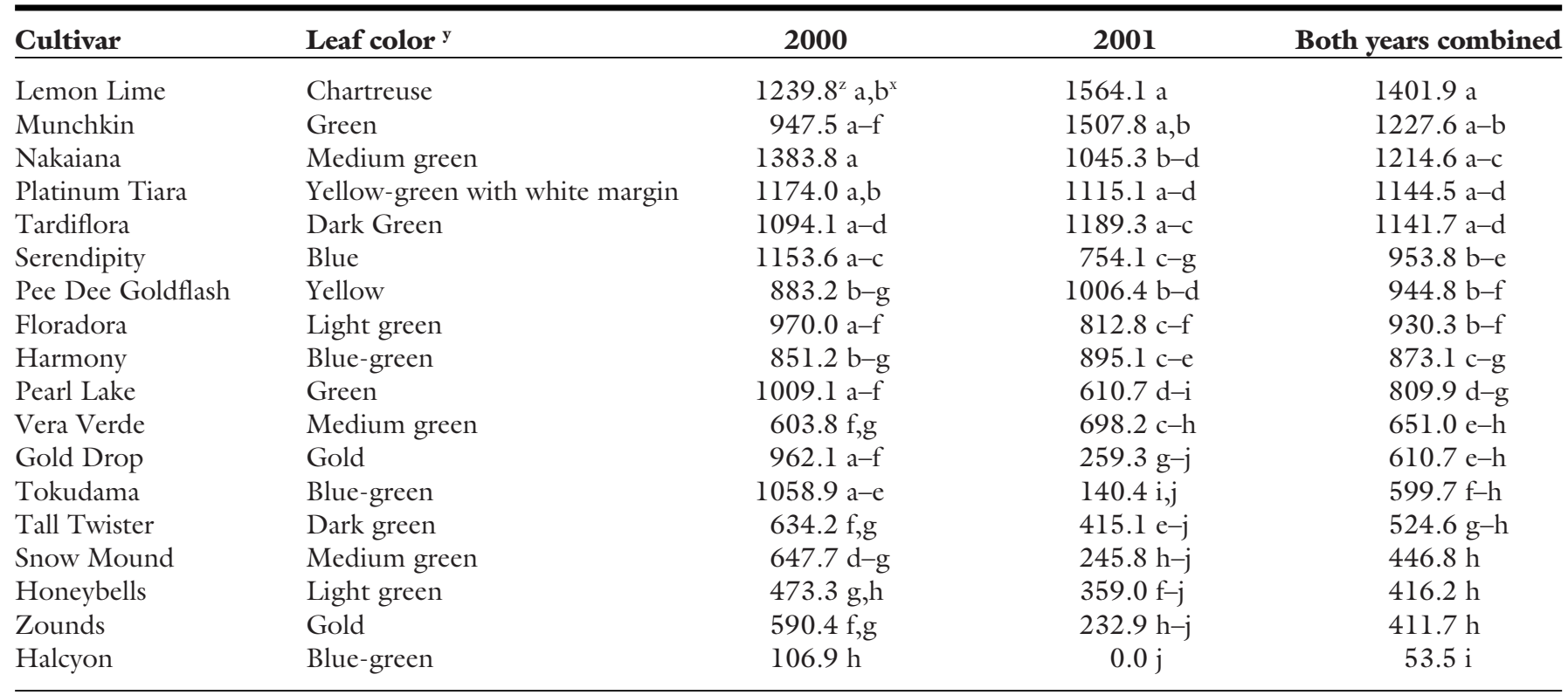

${ }^{\mathrm{Z}}$ Larger AUDPC values indicate more severe disease development.

yColor descriptions from Wade, 2002.

${ }^{x}$ Means followed by the same letter are not significantly different at $P=0.05$ according to the least square difference (LSD) test.

with a carrot disk infested with $S$. rolfsii var. delphinii, however, resulted in consistent disease development. Covering the soil surface with plastic further increased disease severity by reducing moisture loss from the inoculum and increasing relative humidity.

SCREENING OF CULTIVARS FOR DISEASE RESISTANCE. A wide range of resistance responses were observed among cultivars (Table 1). 'Lemon Lime', 'Munchkin', 'Tardiflora', 'Platinum Tiara', and 'Nakaiana' were the most susceptible, whereas 'Halcyon' was clearly the most resistant cultivar. 'Snow Mound', 'Honeybells', and 'Zounds' exhibited moderate resistance in both years of the trial. Resistance ratings for given cultivars were generally similar between the two trials; an exception was 'Tokudama' which exhibited relatively severe disease development in 2000 but was among the least diseased cultivars in 2001. No cultivar showed complete resistance in both years.

Plant height showed a significant $(P<0.05)$ positive correlation with disease severity in 2000 , but neither height nor spread of foliage was correlated with disease severity in 2001.

\section{Discussion}

This report is the first systematic evaluation of hosta cultivars for resistance to petiole rot caused by $S$. rolfsii var. delphinii. The relatively wide range of resistance among the 18 cultivars tested is encouraging evidence that hosta germplasm contains sufficient genetic variation to breed enhanced resistance to $S$. rolfsii var. delphinii. The consistently high level of resistance by cultivars such as 'Halcyon' and 'Zounds' suggests that these could be used in resistance breeding efforts, and merit further study to characterize the basis of resistance.

Although anecdotal reports have linked blue leaf color in host cultivars to petiole rot resistance, this was not confirmed in our study. Blue leaf color in hosta is caused by the diffusion of light through thick cuticular wax (Grenfell, 1996). Cuticle wax is a trait of many plants that can act as a resistance mechanism (Haung, 2001). The most resistant cultivar, 'Halcyon', is a blue-leaved cultivar, but the other blue cultivars ('Serendipity', 'Harmony', and 'Tokudama') included in the study showed a wide range of disease development. A greater number of cultivars need to be tested in order to clarify the effect, if any, of cuticular wax on resistance.

Plant size has also been suggested by observational evidence to be proportional to crown rot resistance. Our study provided no conclusive evidence of such a relationship. More trials are needed to determine if there is a relationship between hosta size and resistance.

In preliminary trials using sclero- tia as inoculum, most had surface contamination with Penicillium that reduced germination. Surface sterilization with sodium hypochlorite is known to induce nutrient leakage from sclerotia (Linderman and Gilbert, 1973). This leakage can increase contamination problems by providing a nutrient source for other organisms such as Penicillium. The contamination we observed decreased germination, which resulted in erratic infection of inoculated plants. Using plugs of mycelium as inoculum was also ineffective since drying of the agar killed the pathogen. Using an autoclaved carrot disk infested by an agar plug containing the pathogen provided reliable, uniform inoculation of all plants. Covering the soil surface with plastic increased relative humidity, which reduced drying of the carrot/agar inoculum plug.

Further research should not only expand the range of hosta cultivars tested, but also reevaluate the tested cultivars with outdoor field trials. Attempting to relate morphological traits such as petiole thickness, cuticle wax composition and thickness, or other host physiological features could help to define the nature of resistance to $S$. rolfsii var. delphinii. Future studies should also include $S$. rolfsii as well as S. rolfsii var. delphinii; this knowledge would benefit a wider geographic range of hosta growers, including those in the southern U.S. 


\section{Literature cited}

Aycock, R. 1966. Stem rot and other diseases caused by Sclerotium rolfsii. N.C. Agr. Expt. Sta., Raleigh, Tech. Bul. 174.

Canaday, C.H. 1999. Production of sclerotia of Sclerotium rolfsii on brown wrapping paper for use in studies of southern blight of vegetable crops. Phytopathology 89:S11 (abstr.).

Cline, M.N. and B.J. Jacobsen. 1983. Methods for evaluating soybean cultivars for resistance to Sclerotinia sclerotiorum. Plant Dis. 67:784-786.

Draheim, J. 1997. Serious hosta disease. Mich. State Univ. Ext. Landscape Alerts 71897007

Edmunds, B., M. Gleason, and U. Schuch. 2000. Crown rot: A serious disease of hosta and other ornamentals. Iowa State Univ. Ext. Publ. SUL 8. 14 Nov. 2002 http:// www.extension.iastate.edu/Publications/ SUL8.pdf.

Gomez, KA. and A.A. Gomez. 1984. Statistical procedures for agricultural research. Wiley, New York.

Grenfell, D. 1996. The gardener's guide to growing hostas. Timber Press, Portland, Ore.

Harlton, C.E., C.A. Levesque, and Z.K. Punja. 1995. Genetic diversity in Sclerotium (Athelia) rolfsii and related species. Phytopathology 85(10):1269-1281.

Haung, J. 2001. Plant pathogenesis and resistance. Kluwer Academic Publishers, Dordrecht, The Netherlands.

Javed, Z.U.R. and J.R. Coley-Smith. 1973. Studies on the germination of sclerotia of Sclerotium delphinii. Trans. Brit. Mycol. Soc. 60:441-451

Linderman, R.G. and R.G. Gilbert. 1973. Behavior of sclerotia of Sclerotium rolfsii produced in soil or in culture regarding germination stimulation by volatiles, fungistasis, and sodium hypochlorite treatment. Phytopathology 63:500-504.

Okabe, I., C. Morikawa, N. Matsumoto, and K. Yokoyama. 1998. Variation in Sclerotium rolfsii isolates in Japan. Mycoscience 39:399-407.

Punja, Z.K. 1985. The biology, ecology, and control of Sclerotium rolfsii. Annu. Rev. Phytopathol. 23:97-127.

Punja, Z.K. and A. Damiani. 1996. Comparative growth, morphology, and physiology of three Sclerotium species. Mycologia 88(5):694-706.

Steel, R.G.D., J.H. Torrie, and D.A. Dickey. 1997. Principles and procedures of statistics: A biometrical approach. McGraw-Hill, Boston, Mass.

Wade, V.R. 2002. The American hosta guide, 2002: Descriptive list and catalog. Wade and Gatton Nurseries, Bellville, Ohio.
Influence of

Fertilizer Placement on Plant Quality, Root Distribution, and Weed Growth in Container-grown Tropical Ornamental Plants

\author{
Timothy K. Broschat and \\ Kimberly K. Moore
}

\begin{abstract}
Additional INDEX WORDs. Hibiscus rosasinensis, Jasminum multiflorum, Plumbago auriculata, Pseuderanthemum laxiflorum, Dypsis lutescens, Chamaedorea seifrizii, Caryota mitis, Archontophoenix alexandrae, Wodyetia bifurcata, Ptychosperma macarthurii, controlledrelease fertilizers
\end{abstract}

Summary. In two experiments, chinese hibiscus (Hibiscus rosa-sinensis), bamboo palm (Chamaedorea seifrizii), areca palm (Dypsis lutescens), fishtail palm (Caryota mitis), macarthur palm (Ptychosperma macarthurii), shooting star (Pseuderanthemum laxiflorum), downy jasmine (Jasminum multiflorum), plumbago (Plumbago auriculata), alexandra palm

(Archontophoenix alexandrae), and foxtail palm (Wodyetia bifurcata) were transplanted into $6.2-\mathrm{L}$ (2-gal) containers. They were fertilized with Osmocote Plus 15N-3.9P-10K (12tol4-month formulation) (Expt. 1) or Nutricote Total 18N-2.6P-6.7K (type 360) (Expt. 2) applied by either top dressing, substrate incorporation, or layering the fertilizer just below the transplanted root ball. Shoot dry weight, plant color, root dry weights in the upper and lower halves of the root ball, and weed shoot dry weight were determined when each species reached marketable size. Optimal fertilizer placement method varied among the species tested. With the exception of areca palm, none of the species tested grew best with incorporated fertilizer. Root dry weights in the lower half of

University of Florida, Dept. of Environmental Horti culture, Fort Lauderdale Research and Education Center, 3205 College Avenue, Fort Lauderdale, FL 33314

Florida Agricultural Experiment Station journal series R-08954. The authors wish to thank Susan Thor and Luci Fisher for their assistance in this study. the root ball for chinese hibiscus, bamboo palm, and downy jasmine were greatest when the fertilizer was layered and root dry weights in the upper half of the root ball were greatest for top-dressed chinese hibiscus. Weed growth was lower in pots receiving layered fertilizer for four of the six palm species tested.

A lthough numerous papers discuss the effects of controlled-release fertilizers on the growth and quality of container-grown plants, relatively few studies have compared the effectiveness of different application methods. These have generally shown that different species grow better with different application methods and that no single application method was consistently superior (Blessington et al., 1981; Cobb, 1985; Conover and Poole, 1985; Yeager and Ingram, 1987). Other studies have shown that response to fertilizer placement is affected by irrigation method (Coleman et al., 1978; Hicklenton, 1990; Klock-Moore and Broschat, 1999).

There have been no published comparisons of fertilizer placement effects on the growth and quality of containergrown palms. Although some palms produce rather fibrous root systems that uniformly fill the container, other species have relatively coarse, unbranched root systems that tend to be concentrated near the bottom of the container (T.K. Broschat, personal observation). A preliminary study on fertilizer placement effects suggested that palms may grow better with fertilizer layered just below the transplanted root ball, whereas dicot shrubs such as chinese hibiscus and ixora (Ixora spp.) may perform better with top-dressed or incorporated fertilizer (T.K. Broschat and H. Donselman, unpublished data). They also observed that fewer weeds grew in pots with layered fertilizer than with top-dressed or incorporated controlledrelease fertilizer. Thus the purpose of this study was to determine how fertilizer placement affects shoot and root growth, root distribution within the container, and weed growth in container-grown tropical ornamental plants.

\section{Materials and methods}

In the first experiment (Expt. 1), liners $[5.1 \mathrm{~cm}$ (2 inches) diameter $x$ $5.1 \mathrm{~cm}$ deep] of chinese hibiscus and $0.5-\mathrm{L}$ (1-pt) pots of bamboo palm, areca palm, fishtail palm, and macarthur 